\title{
Próchnica wczesnego dzieciństwa, ocena wpływu na rozwój narządu mowy - przegląd piśmiennictwa
}

\author{
Early childhood caries, evaluation of the influence on speech organ development - \\ literature review
}

\begin{abstract}
${ }^{1}$ Katedra i Klinika Ortopedii Szczękowej i Ortodoncji, Uniwersytet Medyczny im. Karola Marcinkowskiego w Poznaniu Chair and Department of Maxillofacial Orthopaedics and Orthodontics, Poznan University of Medical Sciences

${ }^{2}$ Studenckie Koło Naukowe Ortopedii Szczękowej i Ortodoncji, Uniwersytet Medyczny im. Karola Marcinkowskiego w Poznaniu Students Scientific Associatet of Maxillary Orthopaedics and Orthodontics, Poznan University of Medical Sciences

${ }^{3}$ Klinika Wad Rozwojowych Twarzy, Uniwersytet Medyczny im. Karola Marcinkowskiego w Poznaniu

Department of Facial Malformation, Poznan University of Medical Sciences
\end{abstract}

DOI: http://dx.doi.org/10.20883/df.2020.18

\begin{abstract}
STRESZCZENIE
Próchnica wczesnego dzieciństwa (ang. early childhood caries) oznacza każdy ubytek u dziecka poniżej 3 roku życia lub określoną liczbę ubytków na powierzchni zębów mlecznych u dzieci starszych. Występowanie tej odmiany próchnicy u dzieci może wiązać się z absencją w szkole, utrudnionym procesem uczenia sią oraz obniżyć jakość życia dziecka. Niektórzy autorzy wskazują, że wczesna utrata zębów mlecznych wpływa negatywnie na rozwój narządu mowy. Jednakże inni wykazują zdolność do kompensacji i prawidłowego wymawiania głosek przez dzieci, które utraciły zęby sieczne przed 5 rokiem życia. Praca ma na celu wykazanie powiązań między utratą zębów mlecznych, a zaburzeniem prawidłowych warunków okluzyjnych, a co za tym idzie utrudnieniami w artykulacji. Na podstawie 8 zakwalifikowanych do badania prac nie udało się jednoznacznie wykazać związku między wystąpieniem próchnicy wczesnego dzieciństwa a nieprawidłowym, zaburzonym rozwojem mowy u dzieci.
\end{abstract}

Słowa kluczowe: próchnica wczesnego dzieciństwa, zęby mleczne, okluzja.

\section{ABSTRACT}

Early childhood caries refers to any defect in a child under 3 years of age, or a specified number of defects on the surface of the primary teeth in older children. The occurrence of this type of tooth decay in children may be associated with absence from school, difficult learning process and lower the quality of a child's life. Some authors indicate that the early loss of deciduous teeth negatively affects the development of the speech organ. However, others demonstrate the ability to compensate and correctly pronounce the sounds of children who lost their incisors before the age of 5 . The aim of this article is to show the relationship between the loss of deciduous teeth and the disturbance of the correct occlusal conditions, and thus difficulties in articulation. On the basis of 8 studies qualified for this stu$\mathrm{dy}$, it was not possible to clearly demonstrate the relationship between the occurrence of early childhood caries and abnormal, disturbed speech development in children.

Keywords: early childhood caries, primary teeth, occlusion.

\section{Wstęp}

Próchnica wczesnego dzieciństwa (ang. early childhood caries - ECC) oznacza obecność jednego lub więcej zębów mlecznych dotkniętych zmianą próchnicową bez ubytku lub z ubytkiem tkanek zęba, usuniętych lub wypełnionych z powodu próchnicy u dzieci w wieku 71 miesięcy lub młodszych [1]. Każdy ubytek u dziecka w wieku poniżej 3 roku życia; na co najmniej czterech powierzchniach w 3 roku życia; w 4 roku - min. pięć po- wierzchni oraz w 5 roku - min. sześć powierzchni świadczy o ciężkim nietypowym przebiegu (ang. severe early childhood caries - S-ECC) [2]. Według Amerykańskiej Akademii Stomatologii Dziecięcej (AAPD) do powikłań ECC należy zwiększone ryzyko kolejnego ubytku próchnicowego w uzębieniu mlecznym i stałym, hospitalizacja, zwiększony koszt leczenia, absencja w szkole, utrudniona zdolność do uczenia, obniżona jakość życia związana ze zdrowiem jamy ustnej [3]. Jeżeli w wyniku ECC 
z powodu próchnicy dojdzie do ostrego zapalenia okostnej i kości wskazana jest ekstrakcja zęba przyczynowego. Najczęściej ekstrakcji wymagają siekacze mleczne szczęki. Przedwczesna utrata zębów mlecznych powoduje przesuwanie się pozostałych zębów i utratę przestrzeni potrzebnej do prawidłowego wyrzynania się zębów stałych. Im wcześniejsza ekstrakcja, tym większa utrata przestrzeni [4].

Zaburzenia artykulacji - dyslalia, nazywane także wadami wymowy, wadami artykulacyjnymi, to odstępstwo od zgodnej z normą realizacji fonemu - podstawowej jednostki fonologicznej mowy, spowodowane niemożnością jego prawidłowej realizacji. Za jedną z przyczyn powstawania zaburzeń artykulacji uznaje się wady zgryzu oraz nieprawidłowości zębowe [5].

\section{Cel pracy}

Celem pracy jest ustalenie na podstawie przeglądu piśmiennictwa, czy występuje związek pomiędzy ECC a wystąpieniem zaburzeń artykulacji u dzieci.

\section{Materiał i metodologia}

Analizie poddano piśmiennictwo w języku angielskim i polskim z bazy PubMed, Google Schoolar, Główna Biblioteka Medyczna, wpisując słowa kluczowe: speech disorders + early childhood caries, analogicznie w języku polskim: zaburzenia mowy + próchnica wczesnego dzieciństwa, zakładając ich obecność w tytułach lub abstraktach znalezionych publikacji. Po zapoznaniu się z literaturą do pracy zakwalifikowano 8 publikacji. Pod uwagę wzięto publikacje, które analizują wpływ ECC lub przedwczesnej utraty zębów na wystąpienie zaburzeń artykulacji u dzieci. Odrzucono prace, które dotyczyły zaburzeń mowy związanych z wadami rozwojowymi twarzoczaszki i wadami zgryzu. Nie wprowadzono ograniczeń w postaci ram czasowych opublikowanych prac.

\section{Wyniki}

Badania dotyczące wpływu przedwczesnej utraty zębów z powodu ECC na rozwój mowy przedstawiono w formie tabelarycznej (Tabela 1). Uzyskano 8 publikacji opublikowanych w latach 1961-2012. W 6 (5 prac badanych w języku angielskim, 1 praca badana w języku tureckim) na 8 badaniach nie potwierdzono wpływu ECC na nieprawidłowy rozwój mowy. W jednej pracy w języku hiszpańskim i jednej w języku angielskim zaobserwowano u chłopców negatywny wpływ przedwczesnej utraty zębów mlecznych z powodu ECC.

\section{Dyskusja}

Celem pracy było znalezienie powiązania pomiędzy ECC a wystąpieniem nieprawidłowości w rozwoju mowy u dzieci. W żadnej z analizowanych baz naukowych nie udało się znaleźć badań na populacji polskiej. Badania w języku angielskim nie wykazały istotnie statystycznie wpływu ECC na zaburzenia artykulacji - jednak należy zwrócić uwagę, że badania Karoluk i wsp. [9] oraz Leake i wsp. [11] były badaniami ankietowymi, które cechuje mała swoistość i czułość. Badania oparte wyłącznie na subiektywnych odczuciach rodziców pacjentów nie powinny być brane pod uwagę do wyciągania ogólnych wniosków. Riekman i wsp. [8] zasugerowali, że w im młodszym wieku dochodzi do ekstrakcji z powodu próchnicy, tym większe ryzyko wystąpienia nieprawidłowości w rozwoju mowy. Ich badania nie potwierdziły jednoznacznie tej tezy, ale znalazły potwierdzenie w badaniach Gable i wsp. [10]. Badania Riekman i wsp. [8] i Gable i wsp. [10] posiadały małą grupę badaną oraz krótki był czas obserwacji, co czyni je mało wiarygodnymi. Badania Lamberghini i wsp. [13] prowadzone jednocześnie w języku hiszpańskim i angielskim u chłopców dwujęzycznych wykazały negatywny wpływ przedwczesnej ekstrakcji na mowę, jednak w przypadku dziewczynek nie potwierdzono tej zależności. Badania prowadzone przez Gable i wsp. [10] były jedynymi wśród analizowanych prac, w których przeprowadzono badanie słuchu i ocenę zgryzu w celu wykluczenia wpływu nieprawidłowego słuchu i wady zgryzu na rozwój mowy u dzieci. Turgut i wsp. [12] wykazali w swoich badania, że dzieci poniżej 5 roku życia, pomimo przedwczesnej utraty zębów siecznych, mają zdolność do kompensacji i prawidłowego wymawiania głosek. Ze względu na niską jakość analizowanych badań nie można jednoznacznie stwierdzić, czy istnieje wpływ ECC na zaburzenia rozwoju mowy u dzieci [14]. Należy wykonać dalsze badania z większą liczbą osób badanych oraz dłuższym czasem obserwacji. Prawdopodobnie w zależności od języka, którym posługują się badani pacjenci, wyniki mogą się od siebie różnić.

\section{Podsumowanie}

Na podstawie analizowanego piśmiennictwa nie można stwierdzić, że próchnica wczesnego dzieciństwa wpływa niekorzystnie na rozwój mowy. Autorzy wskazują potrzebę przeprowadzenia bardziej szczegółowych badań uwzględniających współpracę między lekarzami dentystami, specjalistami foniatrii i logopedii. 


\begin{tabular}{|c|c|c|c|c|c|c|c|c|}
\hline 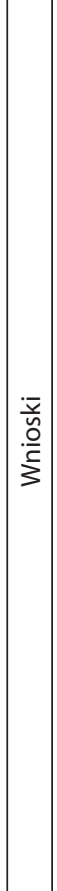 & 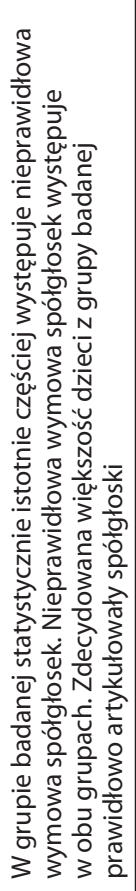 & 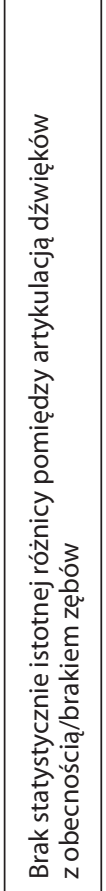 & 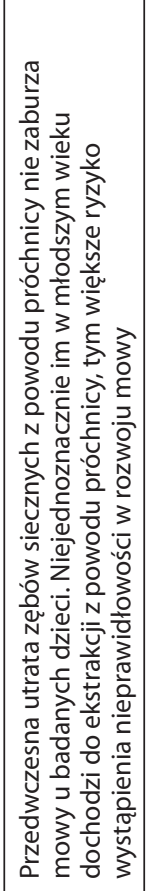 & 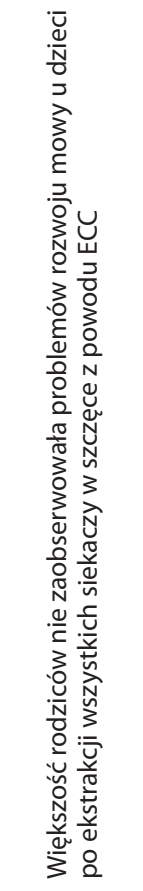 & 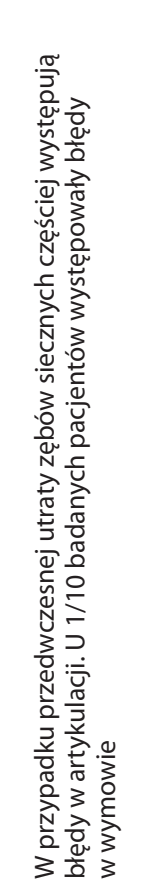 & 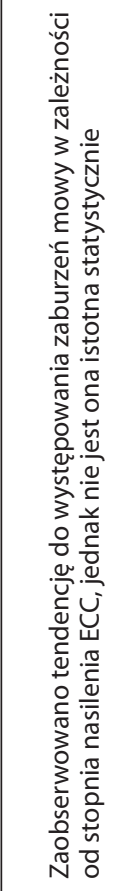 & 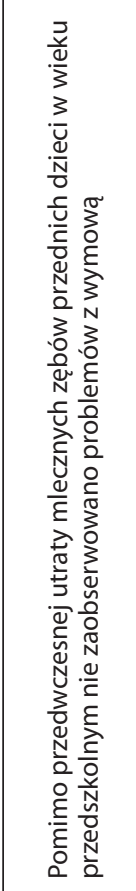 & 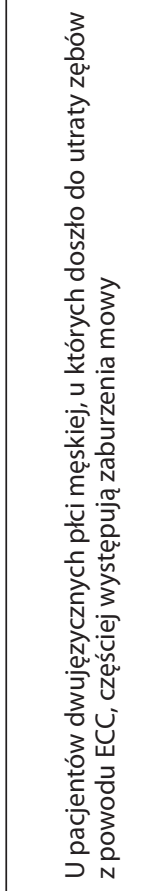 \\
\hline & 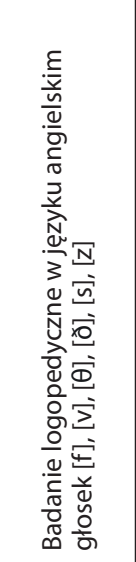 & 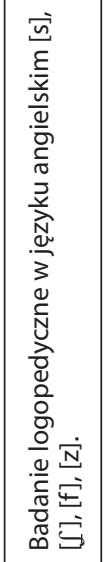 & 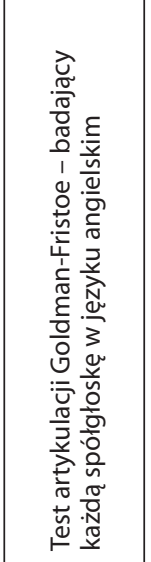 & 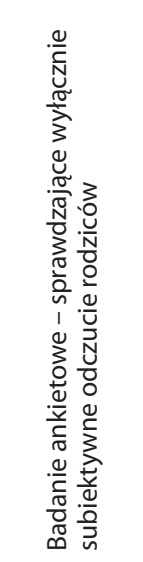 & 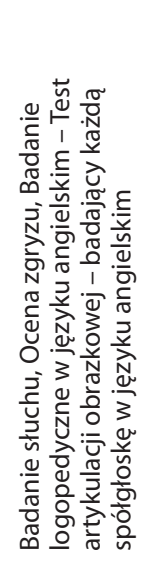 & 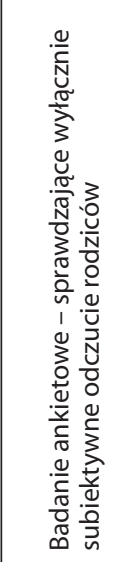 & 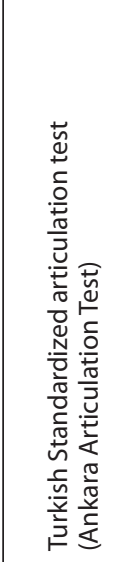 & 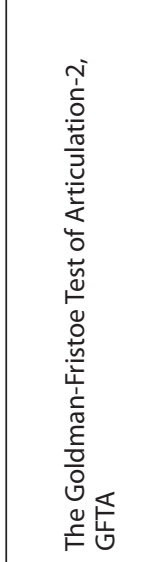 \\
\hline $\begin{array}{l}0 \\
\frac{\pi}{0} \\
\frac{\pi}{0} \\
0 \\
0 \\
0 \\
\frac{2}{0} \\
0\end{array}$ & 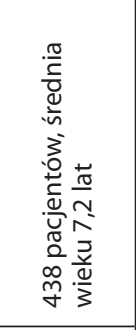 & 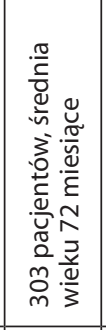 & 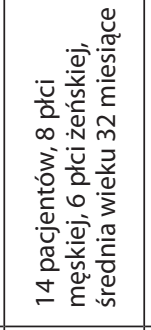 & 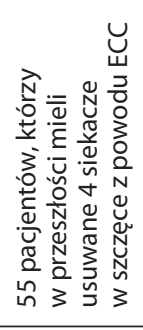 & 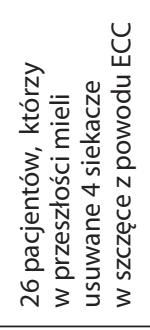 & 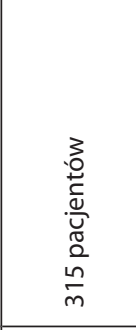 & 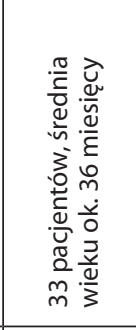 & 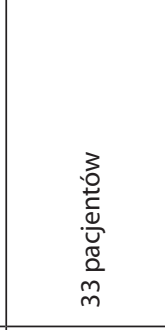 \\
\hline 壳 & 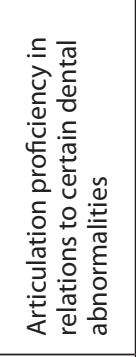 & 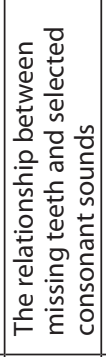 & 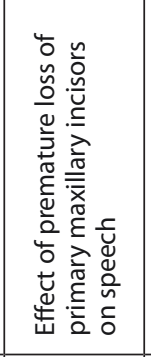 & 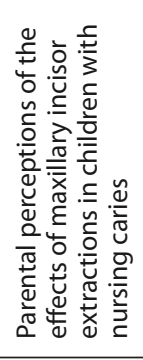 & 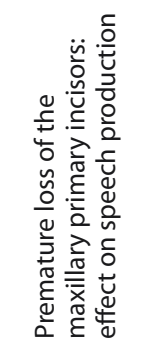 & 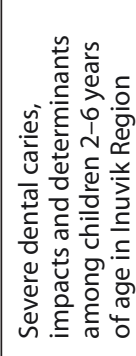 & 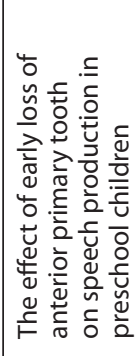 & 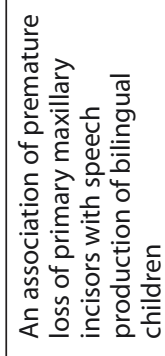 \\
\hline 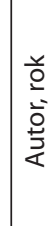 & 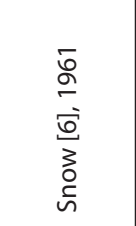 & 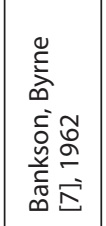 & 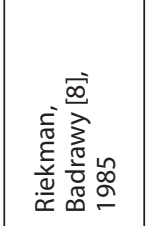 & 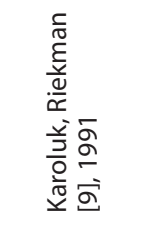 & 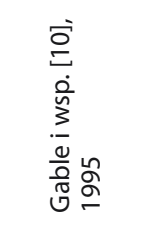 & 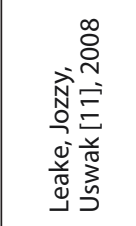 & 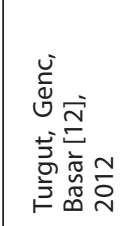 & 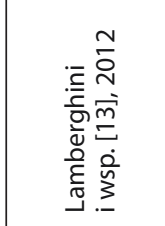 \\
\hline
\end{tabular}




\section{Oświadczenia}

Oświadczenie dotyczące konfliktu interesów

Autorzy deklarują brak konfliktu interesów w autorstwie oraz publikacji pracy.

\section{Źródła finansowania}

Autorzy deklarują brak źródeł finansowania.

\section{Piśmiennictwo}

[1] Adair SM. Epidemiology and mechanisms of dental disease. In: Pinkham JR, Casamassimo PS, Fields HW, McTique DJ, Nowak AJ, editors. Pediatric dentistry infancy through adolescence. 4th ed. St Louis (MO): Elsevier Saunders; 2005. p. 199-205.

[2] Folayan M, Olatubosun S. Early Childhood Caries - A diagnostic enigma. Eur J Paediatr Dent. 2018;19(2):88. doi:10.23804/ejpd.2018.19.02.00.

[3] Policy on Early Childhood Caries (ECC): Classifications, Consequences, and Preventive Strategies. Pediatr Dent. 2016;38(6):52-54.

[4] Cobourne MT, Williams A, Harrison M. National clinical guidelines for the extraction of first permanent molars in children. Br Dent J. 2014;217(11):643-648. doi:10.1038/sj.bdj.2014.1053.

[5] D. Pluta Wojciechowska, Dyslalia obwodowa. Diagnoza, i terapia logopedyczna wybranych form zaburzeń, Wydawnictwo Ergo-Sum, Bytom 2017, s. 85.

[6] Snow K: Articulation proficiency in relation to certain dental abnormalities. J Speech Hear Dis 26:209$12,1961$.

[7] Bankson NW, Byrne MC: The relationship between missing teeth and selected consonant sounds. J Speech Hear Dis 27:341-48,1962.

[8] Riekman GA, el Badrawy HE. Effect of premature loss of primary maxillary incisors on speech. Pediatr Dent. 1985;7(2):119-122.

[9] Koroluk LD, Riekman GA. Parental perceptions of the effects of maxillary incisor extractions in children with nursing caries. ASDC J Dent Child. 1991;58(3):233-236.

[10] Gable TO, Kummer AW, Lee L, Creaghead NA, Moore LJ. Premature loss of the maxillary primary incisors: effect on speech production. ASDC J Dent Child. 1995;62(3):173-179.

[11] Leake J, Jozzy S, Uswak G. Severe dental caries, impacts and determinants among children 2-6 years of age in Inuvik Region, Northwest Territories, Canada. J Can Dent Assoc. 2008;74(6):519.

[12] Turgut MD, Genc, GA, Basar F.The effect of early loss of anterior primary tooth on speech production in preschool children. Turk J Med Sci 2012;42(5):867-75.

[13] Lamberghini F, Kaste LM, Fadavi S, Koerber A, Punwani IC, Smith EB. An association of premature loss of primary maxillary incisors with speech production of bilingual children. Pediatr Dent. 2012;34(4):307-311.

[14] Hyde, Amy C, Lynne Moriarty, Annie G Morgan, Lamis M Elsharkasi and Chris Deery. "Speech and the dental interface." Dental update 45 (2018):795-803.

Zaakceptowano do edycji: 2020-10-06 Zaakceptowano do publikacji: 2020-10-06

\author{
Adres do korespondencji: \\ Michał Kliński \\ Studenckie Koło Naukowe Ortopedii Szczękowej \\ i Ortodoncji, \\ Uniwersytet Medyczny im. Karola Marcinkowskiego \\ w Poznaniu \\ ul. Bukowska 70 \\ 60-812 Poznan \\ tel.: 664-771-963 \\ e-mail: klinskimichal@gmail.com
}

